\title{
Desain Antena Mikrostrip Bentuk Segi Empat Untuk Antena Syntentic Aperture Radar (SAR)
}

\author{
Junas Haidi, Hendy Santosa, Alex Surapati \\ Program Studi Teknik Elektro, Fakultas Teknik Universitas Bengkulu \\ E-mail: junas.haidi@unib.ac.id
}

\section{AbSTRACT}

This paper is designing a rectangular microstrip antenna for Synthetic Aperture Radar (SAR) antenna applications operating at a frequency of $10 \mathrm{GHz}$ with the material used is Duroid $4350 \mathrm{~b}$ substrate. The results show SAR antenna output was obtained with a return loss value of $-\mathbf{4 2 . 1 3} \mathrm{dB}$, VSWR of 1.0158, antenna impedance of $48.67 \Omega$, bandwidth of $0.377 \mathrm{GHz}$, Half Power Beamwidth (HPBW) of 150 and Gain of $10.5 \mathrm{dBi}$. The antenna output parameters produce a reasonably good antenna standard. However, SAR antenna with a simple rectangular shape needs to be improved, especially the gain and HPBW antenna values, because the SAR antenna must have a large gain and a small HPBW values.

Keywords- Microstrip Antenna, Radar, SAR.

\section{ABSTRAK}

Paper ini membahas tentang perancang antena mikrostrip bentuk segi empat untuk aplikasi antena SAR yang berkerja difrekuensi $10 \mathrm{GHz}$ dengan material yang digunakan adalah substrat Duroid 4350b. dari hasil penelitian didaptkan output antena SAR dengan nilai return loss sebesar $-42,13 \mathrm{~dB}$, VSWR sebesar 1,0158, impedansi antena $48,67 \Omega$, bandwidth $0,377 \mathrm{GHz}$, HPBW sebesar $15^{\circ}$ dan Gain 10,5 dBi. Dari parameter output antena yang dihasilkan, telah memenuhi standar antena yang cukup baik. Dalam perancangan antena SAR bentuk segi empat ini masih perlu dikembangkan lagi terutama nilai gain dan HPBW antena, karena antena SAR harus memiliki gain yang besar dan nilai HPBW yang kecil..

Kata kunci : Microstrip Antenna, Radar, SAR

\section{Pendahuluan}

Synthetic Aperture Radar (SAR) digunakan untuk penginderaan jarak jauh pada permukaan bumi[1] dengan menggunakan citra yang mempunyai resolusi tinggi, digunakan kondisi siang dan malam serta bebas dari pengaruh cuaca hujan, awan dan kabut[2] di
TABEL 1

SPESIFIKASI SUBSTRAT YANG DIGUNAKAN

\begin{tabular}{cc}
\hline Jenis Substrat & Duroid 4350b \\
\hline Konstanta Dielektrik Relatif $\left(\varepsilon_{r}\right)$ & 3,48 \\
Faktor Dispasi & 0,0265 \\
Ketebalan Substrat $(\mathrm{h})$ & $1.524 \mathrm{~mm}$ \\
\hline
\end{tabular}

aplikasi untuk berbagai tujuan seperti perubahan iklim, pemantauan lingkungan dan kondisi bumi saat ini[3]. Sistem SAR bekerja digelombang mikro dengan frekuensi kerja $0,3 \mathrm{GHz}$ sampai $300 \mathrm{GHz}$ [4]. SAR terdiri dari dua bagian yaitu pemancar (transmitter) dan penerima (receiver), Bagian pemancar akan mengirimkan gelombang elektromagnetik secara terus menerus yang dipantulkan kepermukaan bumi yang menjadi pengamatan, kemudian antena penerima akan menangkap gelombang elektromagnetik yang dipantulkan dari permukaan bumi direkam dan diproses ketahapan berikunya [4][5].

Antena SAR harus memiliki bandwidth yang sempit untuk mendapatkan resulosi gambar yang tinggi dan target objek yang diamati akan semakin jelas[6]. Dalam membuat antena SAR harus diperhitungkan juga nilai ekonomis, pada penelitian yang dilakukan dalam mendesain antena SAR digunakan substart Duroid 4350b yang harganya cukup murah. Sehingga dilakukan penelitian antena SAR yang murah dan memenuhi standar antena yang telah ditentukan.

Paper ini menunjukkan perancangan antenna mikrostrip single layer dengan bentuk segi empat. Patch radiasinya di umpan dengan jalur mikrostrip pada bagian atas substrat Duroid 4350b. Untuk meningkatkan nilai gain dan HPBW dilakukan modifikasi bentuk antena mikrostrip segi empat.

\section{Kerangka Teoritis Dan Pengembangan Hipotesis}

A. Desain Antena SAR Bentuk Segi Empat.

Antena SAR yang dibuat bekerja pada frekuensi 10 $\mathrm{GHz}$ dengan material yang digunakan adalah substrat Duroid 4350b. spesifikasi substrat yang digunakan dapat dilihat pada Tabel 1. 
Untuk merancang dimensi lebar patch antena SAR yang bekerja difrekuensi $10 \mathrm{GHz}$ dapat dilakukan perhitungan dengan menggunakan Persamaan 1[7]. Berdasarkan hasil perhitungan diperoleh lebar patch sebesar 10,02 mm.

$$
W=\frac{c}{2 f r \sqrt{\frac{\left(\varepsilon_{r}+1\right)}{2}}}
$$

Sementara itu, nilai panjang patch dapat dicari dengan menggunakan Persamaan 2, 3, 4 dan 5[7]. Berdasarkan hasil perhitungan diperoleh panjang patch sebesar 6,79 $\mathrm{mm}$.

$$
\begin{aligned}
& L=L_{\text {eff }}-2 \Delta L \\
& L_{\text {eff }}=\frac{c}{2 f r \sqrt{\varepsilon_{\text {reff }}}} \\
& \Delta L=0,412 h\left[\frac{\left(\varepsilon_{\text {reff }}+0,3\right)\left(\frac{W}{h}+0,264\right)}{\left(\varepsilon_{\text {reff }}-0,258\right)\left(\frac{W}{h}+0,8\right)}\right] \\
& \varepsilon_{\text {reff }}=\frac{\varepsilon_{r}+1}{2}+\frac{\varepsilon_{r}-1}{2}\left(\frac{1}{\sqrt{1+\frac{12 h}{W}}}\right)
\end{aligned}
$$

Saluran pencatu yang digunakan pada perancangan awal untuk frekuensi $10 \mathrm{GHz}$ mempunyai impedansi masukan sebesar $50 \Omega[8][9]$. Untuk mencari lebar saluran pencatu pada impedansi $50 \Omega$ digunakan Persamaan 6 dan Persamaan 7[7]. Berdasarkan hasil perhitungan diperoleh lebar saluran pencatu bernilai $3,45 \mathrm{~mm}$.

$$
\begin{aligned}
& W=\frac{2 h}{\pi}\left\{B-1-\ln (2 B-1)+\frac{\varepsilon_{r}-1}{2 \varepsilon_{r}}\left[\ln (B-1)+0,39-\frac{0,61}{\varepsilon_{r}}\right]\right\} \\
& B=\frac{60 \pi^{2}}{Z_{O} \sqrt{\varepsilon_{r}}}
\end{aligned}
$$

Dari hasil perhitungan yang telah dilakukan maka didapat lebar patch, panjang patch dan lebar saluran pencatu persegi panjang sebesar $10,02 \mathrm{~mm}, 6,79 \mathrm{~mm}$ dan 3,45 mm. Dimensi antena mikrostrip bentuk persegi panjang yang didapatkan dari hasil perhitungan dengan teori, masih bisa berubah setelah dilakukan iterasi simulasi dengan bantuan software. Gambar antena SAR berdasarkan hasil dari perhitungan teori dapat dilihat pada Gambar 1 dan ukuran antena SAR dari hasil perhitungan dapat dilihat pada Tabel 2.

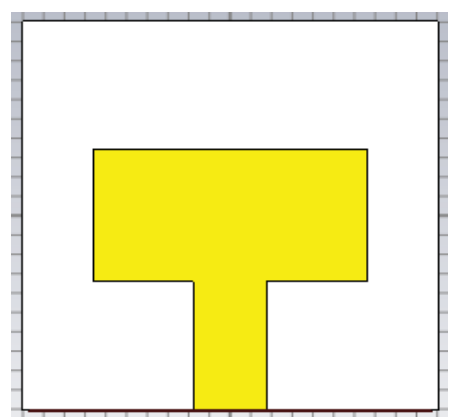

Gambar 1. Bentuk patch antena SAR sebelum diiterasi.

TABEL 2

UKURAN ANTENA SAR DARI HASIL PERHITUNGAN

\begin{tabular}{cc}
\hline Diameter Antena SAR & $\mathbf{m m}$ \\
\hline Panjang Patch & 6,79 \\
Lebar Patch & 10,02 \\
Lebar Saluran Pencatu & 3,45 \\
\hline
\end{tabular}

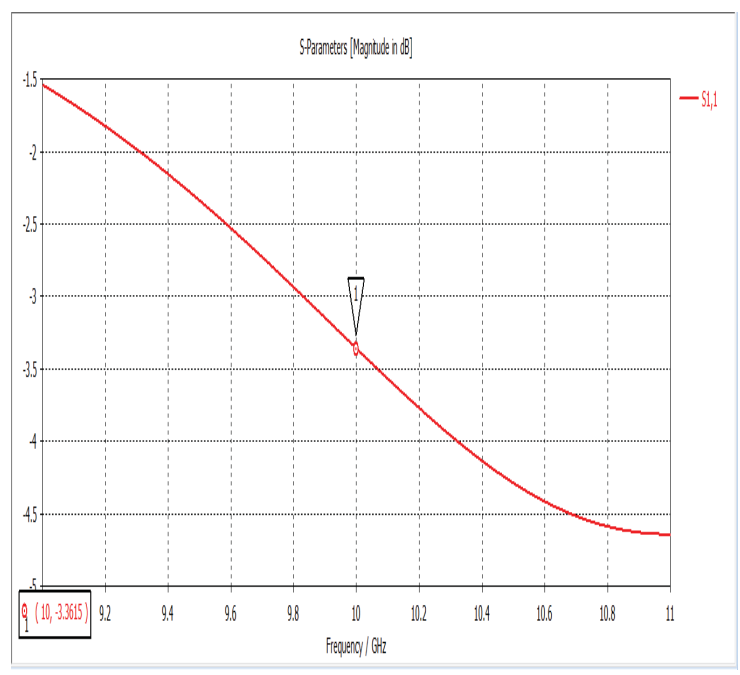

Gambar 2. Return loss sebelum dilakukan iterasi.

\section{B. Simulasi Antena SAR.}

Dari Gambar 1 dan data pada Tabel 2 dilakukan simulasi dengan menggunakan Software. Dari hasil simulasi maka dapat dilihat parameter output antena SAR yang didesain dengan menggunakan perhitungan teori. Adapun parameter output antena SAR return loss antena dapat dilihat pada Gambar 2, grafik VSWR dapat dilihat pada Gambar 3, impedansi antena dapat dilihat dari smitchart pada Gambar 4 dan pola radiasi antena dapat dilihat pada Gambar 5.

Dari Gambar 2 nilai return loss yang didapatkan sebelum dilakukan iterasi pada frekuensi kerja $10 \mathrm{GHz}$ adalah $-3,36 \mathrm{~dB}$. Tentunya nilai return loss yang dihasilkan masih cukup besar dan masih jauh dari nilai setandar minimal yang diizinkan yaitu $-10 \mathrm{~dB}[10]$. Sehingga antena yang didesain masih perlu dilakukan iterasi untuk mendapatkan nilai yang optimal sebelum di pabrikasi menjadi antena SAR. 


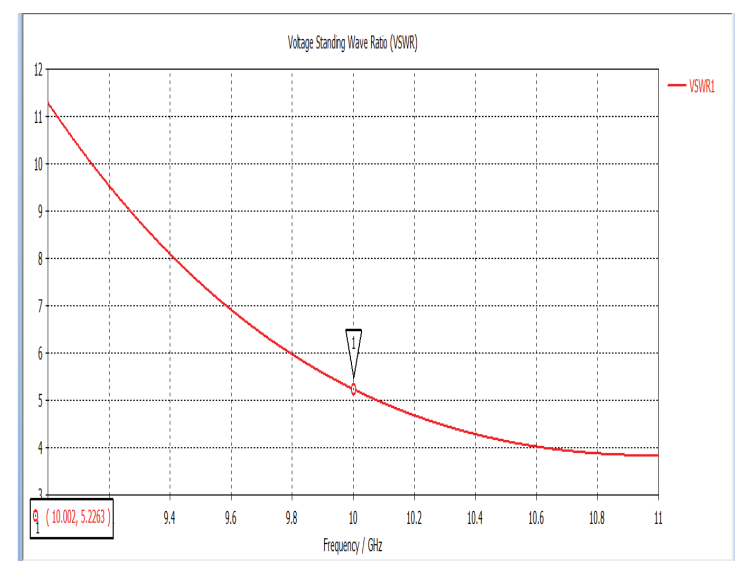

Gambar 3. Grafik VSWR sebelum dilakukan iterasi.

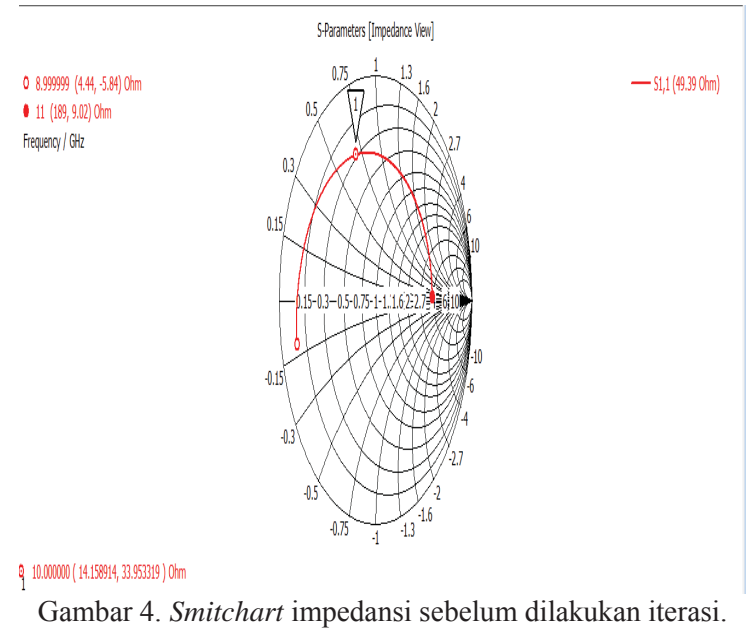

Sebelum dilakukan iterasi maka didapatkan nilai VSWR sebesar 5,22 pada Gambar 3. Dari grafik VSWR tersebut maka antena yang didesain masih sangat jauh untuk memenuhi nilai standar minimal yang diizinkan, dimana setandar VSWR antena adalah 2 sampai dengan 1. Pada penelitian ini ditargetkan nilai VSWR kurang dari 1,2 untuk mendapatkan kinerja antena SAR yang baik, tanpa menimbulkan gelombang balik kepemancar atau transmiter.

Antena SAR yang dirancang menggunakan

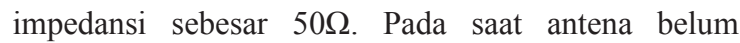
dilakukan iterasi didapatkan impedansi pada Gambar 4


perancangan sebelum dilakukan iterasi sangat jauh dari nilai $50 \Omega$ hal ini apabila antena SAR langsung dibuat maka akan mengakibatkan antena tidak matching atau rugi-rugi daya akan sangat besar, sehingga gelombang elektromagnetik yang dipancarkan sangat lemah. Dengan kondisi impedansi yang jauh dari standar yang telah ditetapkan maka antena SAR yang dirancang masih diperlukan iterasi untuk mendapatkan impedansi yang mendekati $50 \Omega$.

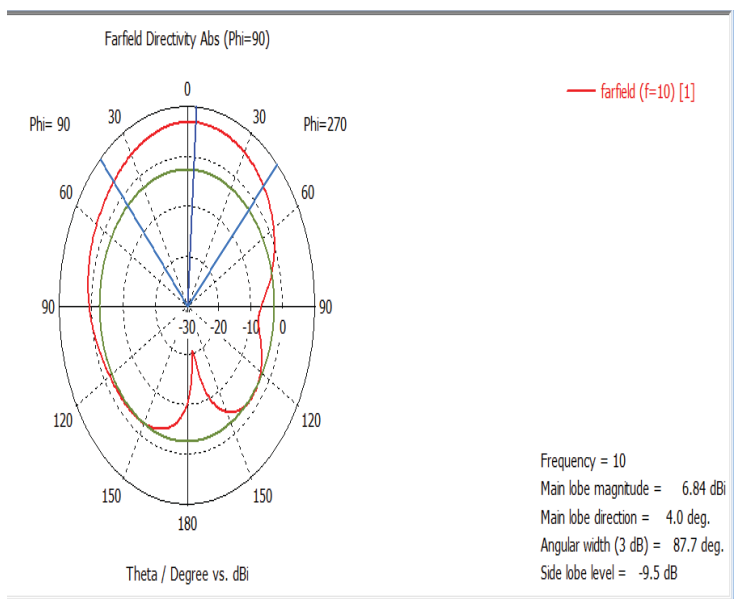

Gambar 5. Polarisasi 2D sebelum dilakukan iterasi.

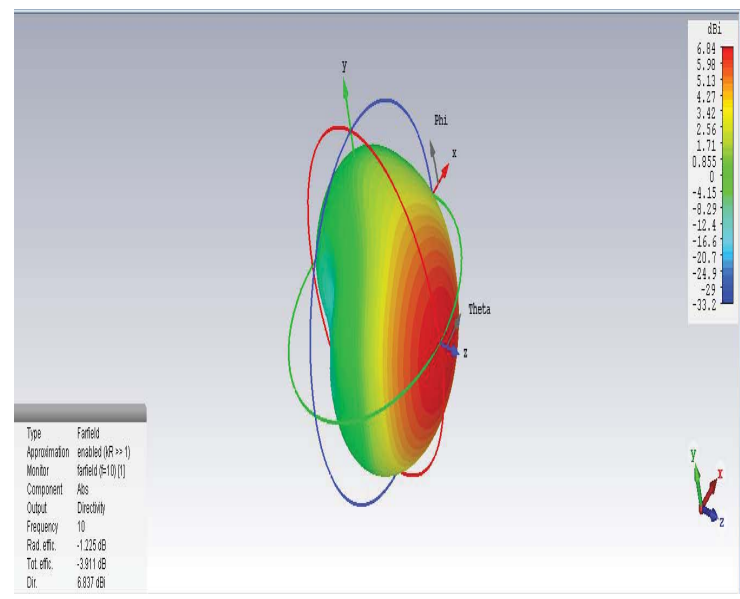

Gambar 6. Polarisasi 3D sebelum dilakukan iterasi.

Dari Gambar 5 dan Gambar 6 dapat dilihat pola radiasi antena yang dihasilkan sebelum diiterasi adalah omni direksional dengan gain 6,84dBi dan HPBW 87,70 . Dari gambar pola radiasi antena yang didesain sebelum dilakukan iterasi daya yang dipancarkan oleh antena SAR masih menyebar kesegala arah sehingga jarak jangkauan gelombang elektromagnetik yang dipancarkan oleh antena menjadi pendek. Untuk mebuat antena SAR mempunyaki pola radiasi direksional atau yang terpusat maka perlu dilakukan metode-metode dalam desain antena SAR sehingga gain yang dihasilkan cukup besar dan HPBW antena menjadi kecil dan diharapkan dalam desain antena SAR didaptkan gain diatas $13 \mathrm{dBi}$ dan HPBW kurang dari $45^{\circ}[11]$. Sehingga pola radiasi yang dihasilkan pada gambar 2 dimensi dan 3 dimensi menjadi pola direksional atau terpusat kesuatu arah.

\section{Iterasi Antena SAR.}

Untuk mendaptkan hasil yang optimal dalam desain antena mikrostrip, maka perlu dilakukan proses iterasi. Proses iterasi ini bertujuan untuk membuat output antena 
TABEL 3

UKURAN ANTENA SAR SETELAH DIITERASI

\begin{tabular}{cc}
\hline Diameter Antena SAR & mm \\
\hline Panjang Patch & 11 \\
Lebar Patch & 14,84 \\
Lebar Saluran Pencatu & 3,5 \\
Lebar Saluran Pencatu & 8 \\
\hline
\end{tabular}

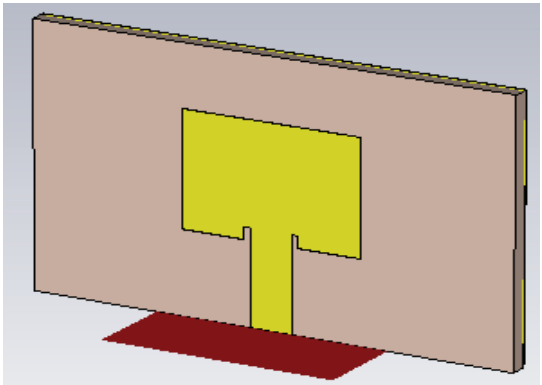

Gambar 7. Antena SAR setelah iterasi

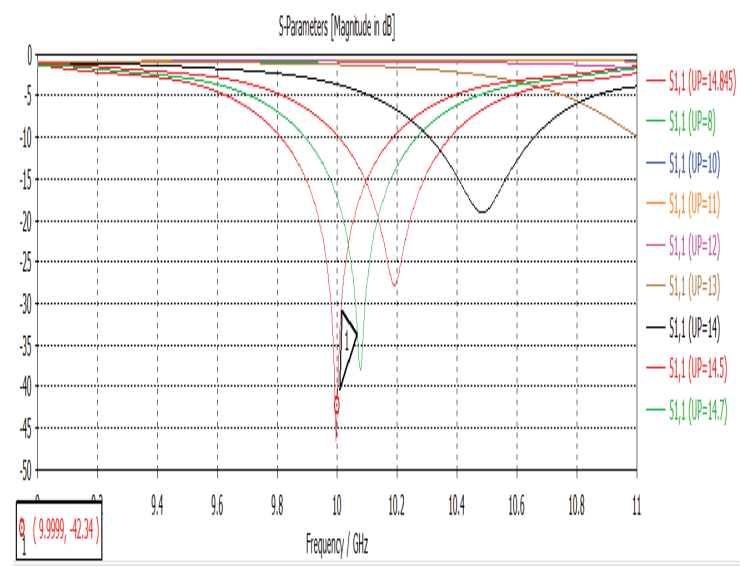

Gambar 8. Proses iterasi nilai return loss

yang didesain memenuhi standar yang telah ditetapkan yaitu retun loss kurang dari $-10 \mathrm{~dB}[12]$, VSWR kurang dari 2 dan nilai impedansi mendekati $50 \Omega$. Proses iterasi desain antena SAR ini dengan cara menambah atau mengurangi ukuran antena dari desain awal yaitu menambah dan mengurangi ukuran panjang dan lebar patch antena segi empat dan dilanjutkan dengan iterasi lebar dan panjang saluran pencatu antena SAR. Dari proses iterasi yang dilakukan didapatkan ukuran antena yang siap di cetak atau dipabrikasi dapat dilihat pada Tabel 3. Dan bentuk antena SAR setelah dilakukan proses iterasi dapat dilihat pada Gambar 7.

Gambar 7 adalah gambar deasain antena SAR yang telah selesai diiterasi dan siap dipabrikasi, untuk output proses iterasi grafik return loss dapat dilihat pada Gambar 8, proses iterasi VSWR dapat dilihat pada Gambar 9 dan proses iterasi impedansi dapat dilihat pada Gambar 10.

4

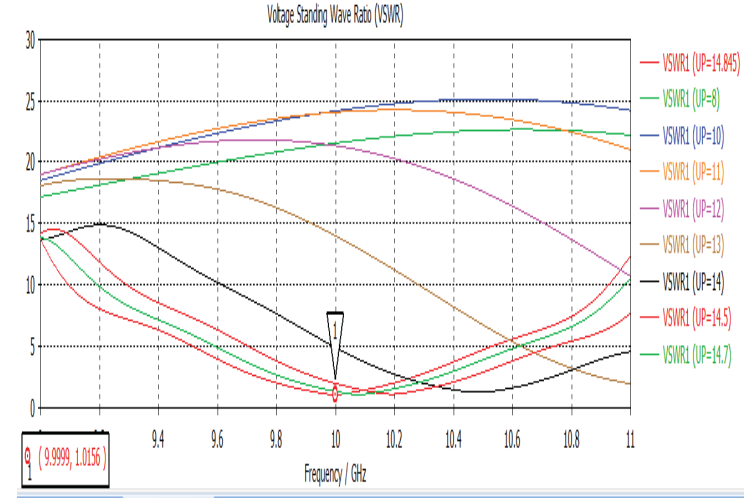

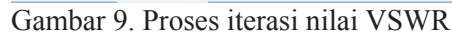



Gambar 10. Proses iterasi nilai impedansi

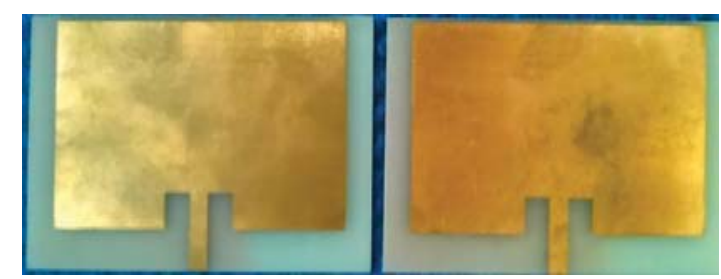

Gambar 11. Antena SAR di frekuensi kerja $10 \mathrm{GHz}$

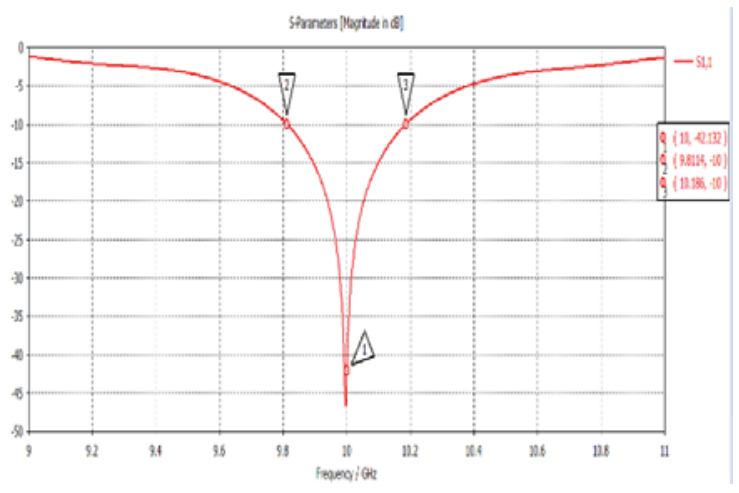

Gambar 12. Retun loss antena SAR

\section{HASIL DAN PEMBAHASAN}

Dari hasil desain, iterasi dan dilakukan pabrikasi antena SAR dapat dilihat pada Gambar 11. Parameter output antena SAR yang didapat nilai return loss dapat dilihat pada Gambar 12, nilai VSWR dapat dilihat pada 


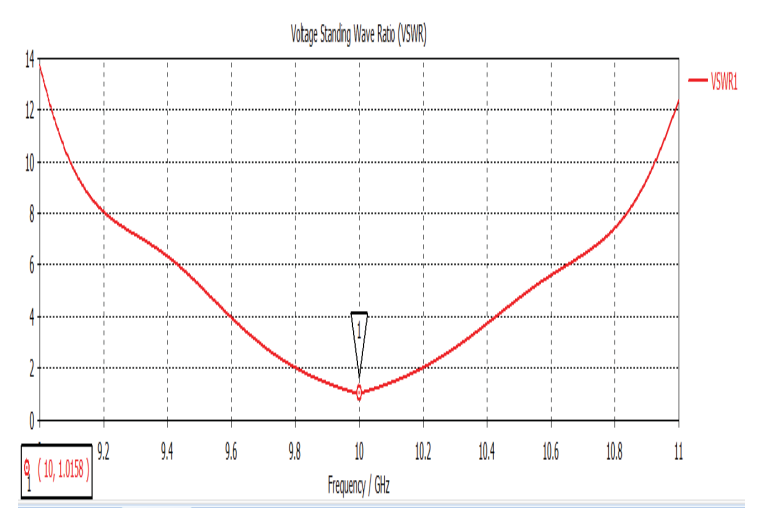

Gambar 13. VSWR antena SAR

O $8.9 \mathrm{~mm}(3.53,0.24) \mathrm{Ohm}$ - II $(5.89,39.2)$ Ohr frequency/ $\mathrm{CHz}$

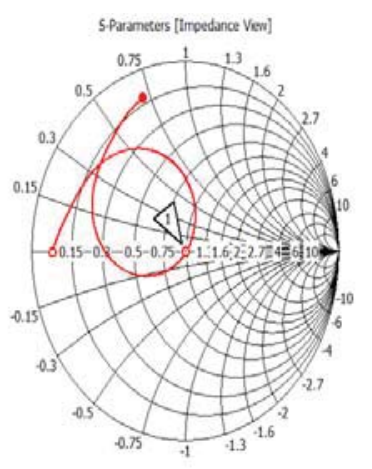

9. 9.997136 ( $48.67446,0.36640$ ) otm

Gambar 14. Impedansi antena SAR

Gambar 13, nilai impedansi antena dapat dilihat pada Gambar 14 dan polaradiasi dapat dilihat pada Gambar 15 dan Gambar 16.

Dari Gambar 12 nilai return loss antena SAR yang dibuat difrekuensi $10 \mathrm{GHz}$ adalah $-42,13 \mathrm{~dB}$. Dari nilai return loss yang didapatkan dari output antena SAR sebesar -42,13 dB, berarti antena SAR yang dibuat telah memenuhi standar return loss antena yaitu kurang dari $10 \mathrm{~dB}[12]$. Nilai return loss yang didapatkan sangat baik sehingga rugi - rugi daya pancar dari antena sangat kecil. Dari gambar grafik return loss diadpatkan bandwidth antena SAR sebesar 0,377 GHz.

Nilai VSWR antena SAR yang dibuat sebesar 1,0158 dimana standar VSWR antena adalah dari 1 samapi dengan 2. Dengan nilai VSWR yang didapat hampir mendekati 1 maka antena SAR yang dibuat sangat baik dikarenakan gelombang balik kepemancar sangat kecil sehingga hampir semua daya terpancar ke udara.

Impedansi antena SAR yang dibuat dari grafik smitchart sebesar $48,67 \Omega$ telah mendekati nilai $50 \Omega$. Dengan impedansi yang didapat sebesar $48,67 \Omega$ maka antena SAR yang dibuat telah memenuhi standar antena dan antena SAR yang dibuat dapat dikatakan matching sempurna dengan rugi-rugi yang dihasilkan cukup kecil.

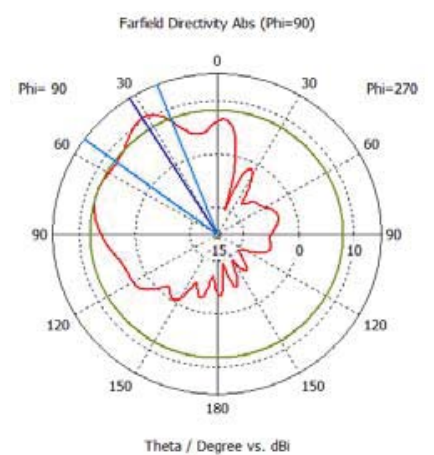

Gambar 15. Pola Radiasi 2D antena SAR



Gambar 16. Pola Radiasi 3D antena SAR

Pola radiasi antena SAR yang dibuat dapat dilihat pada Gambar 15 dan Gambar 16, dari gambar pola radiasi tersebut didapatkan gain sebesar 10,5 dBi. Dengan HPBW sebesar $32,4^{0}$ tentunya dengan nilai HPBW $32,4^{0}$ pola radiasi yang didapatkan sudah directional walaupun belum optimal. Untuk mendapatkan nilai HPBW kurang dari $15^{\circ}$ tentunya harus dilakukan penambahan atau pengembangan desain lagi dengan menggunakan penamabahan patch menggunakan metode array supaya antana SAR lebih sempurna.

\section{PENUTUP}

\section{Kesimpulan}

Dari hasil penelitian antena SAR yang telah dilakukan, didapatkan hasil parameter output antena dengan nilai return loss sebesar $-42,13 \mathrm{~dB}$, VSWR sebesar 1,0158, impedansi antena $48,67 \Omega$, bandwidth $0,377 \mathrm{GHz}$, HPBW sebesar $15^{\circ}$ dan gain 10,5 dBi. Berdasarkan dari nilai output antena SAR yaitu return loss, VSWR, impedansi, maka antena SAR yang dibuat pada frekuensi $10 \mathrm{GHz}$ telah memenuhi standar antena dengan parameter output yang sangat baik, tetapi masih perlu pengembangan lagi dipola radiasi antena untuk meningkatkan nilai gain dan mempersempit nilai HPBW antena SAR. 


\section{REFERENSI}

[1] R. Fitrianto, Y. S. Rohmah, and E. F. A. M. Saputra, "Rancang Bangun Band Pass Filter Frekuensi 1 . $27 \mathrm{GHz}$ untuk Teknologi Synthetic Aperture Radar," vol. 5, no. 2, pp. 149-168, 2017.

[2] A. D. Prasetyo and D. A. Nurmantris, "Rancang Bangun Antena Microstrip Array dengan Teknik Pencatu Proximity Coupler untuk Sersor Circular Polarized Synthetic Aperture Radar (CP-SAR)," Prodi D3 Teknik Telekomunikasi , Fakultas Ilmu Terapan, Universitas Telkom Fakultas Elektro dan Komunikasi , Universitas Telkom Fakultas Ilmu Terapan, Universitas Telkom Abstrak," vol. 1, no. 1, pp. 431-447, 2014.

[3] A. Mukhtar, A. Putri, S. Jayani, J. Cagak, S. $\mathrm{Km}$, and B. Indonesia, "Implementasi Chirp Signal Generator pada FPGA untuk Misi Pencitraan LAPAN Surveillance AircraftSynthetic Radar (LSA-SAR)," pp. 1-14, 2015.

[4] W. Junita Monika Pasaribu, Jalu Tejo Nugroho, "Pemanfaatan Penginderaan Jauh untuk Pemantauan Penurunan Muka Tanah (Land Subsidence),", vol. 7, no. 25-42. 2014.

[5] M. A. Arif, H. Wijanto, and A. D. Prasetyo, "Perancangan Duplexer Jenis Ferrite Circulator untuk Aplikasi Synthetic Aperture Radar (SAR)," vol. 3, no. 2, pp. 1861-1867, 2016.

[6] B. Syihabuddin, D. A. Nurmantris, and A. D.
Prasetyo, "Perancangan Bandpass Filter Pita Sempit pada Frekuensi L-Band untuk Aplikasi Synthetic Aperture Radar ( SAR )," vol. 9, no. 2, pp. 198-203, 2017.

[7] I. Surjati, Antena mikrostrip konsep dan aplikasinya. jakarta: universitas trisakti, 2010.

[8] V. Keerthi, H. Khan, and P. Srinivasulu, "Design of C-Band Microstrip Patch Antenna for Radar Applications Using IE3D," IOSR-JECE, vol. 5, no. 3, pp. 49-58, 2013.

[9] N. Rahman and M. T. Islam, "A Tuning ForkShaped Microstrip Patch Antenna for X-Band Satellite and Radar Applications," IEEE, pp. 1718, 2017.

[10] T. M. Neebha and M. Nesasudha, "Artificial Neural Network Based Design of a Microstrip Patch Antenna for RADAR Applications," IEEE, no. August, pp. 93-98, 2012.

[11] D. Wijoyono, S. Ramadhanty, D. Rakmatullah, and F. Y. Zulkifli, "Uniform Microstrip Array Antenna with Low Sidelobe Level for Coastal Surveillance Radar Application at 9. 37 - 9. 43 GHz," IEEE, pp. 22-25, 2017.

[12] S. Gupta, S. S. Dhillon, P. Khera, and A. Marwaha, "Dual band u-slotted microstrip patch antenna for c band and x band radar applications," in IEEE, 2013, pp. 41-45. 